\title{
O papel e o lugar da didática específica na formação inicial do professor de matemática*
}

\author{
ANA TERESA DE CARVALHO CORREA DE OLIVEIRA \\ Universidade Federal do Rio de Janeiro, Rio de Janeiro, RJ, Brasil
}

DARIO FIORENTINI

Universidade Estadual de Campinas, Campinas, SP, Brasil

RESUMO

Neste artigo trazemos para debate questões acerca da formação inicial de professores de matemática valendo-nos de uma pesquisa que objetivou conhecer, analisar, interpretar e descrever o pensamento, os saberes e as práticas que vêm sendo mobilizados, produzidos e desenvolvidos pelos formadores de professores que atuam na disciplina de didática especial de matemática em cursos de licenciatura em matemática. Visamos interpretar, analisar e compreender a natureza do conhecimento que tem sido privilegiado na(s) disciplina(s), sua importância e relação com a prática de ensinar e aprender matemática nas escolas. Entrevistamos dez formadores atuantes nessa disciplina. Priorizamos no texto o que conhecemos de suas práticas formativas, do seu pensamento acerca da importância da disciplina didática especial, destacando as (in)diferenciações entre as disciplinas didático-pedagógicas; seu lugar curricular no curso; as concepções e práticas formativas privilegiadas na disciplina e no curso.

PALAVRAS-CHAVE

didática especial; formação inicial; licenciatura em matemática.

* Este estudo contou com financiamento do Conselho Nacional de Desenvolvimento Científico e Tecnológico (CNPq). 


\title{
THE ROLE AND PLACE OF SPECIFIC DIDACTIS IN THE INITIAL FORMATION OF MATHEMATICS TEACHERS
}

\begin{abstract}
This paper presents some issues to the debate on the initial education of Mathematics teachers, derived from a research that aimed at knowing, analyzing, interpreting and describing the thought, the knowledge and the practice that have been being mobilized, produced and developed by teacher educators who teach Special Didactics of Mathematics in teacher education courses of Mathematics. We intend to analyze and understand the nature of the knowledge that has prevailed in that subject, its importance and relation to the practice of teaching and learning Mathematics in school settings. We interviewed ten teacher educators in this subject. This article prioritizes the debate about their formative practice, their ideas about the importance of the Special Didactics and highlights, above all, the (in)difference among the didactic-pedagogical subjects, their place in the course curriculum, the conceptions and formative practice which prevail in the subject and in the course.
\end{abstract}

KEYWORDS

special didactics; preservice teacher education; teacher education in mathematics.

\section{EL PAPEL Y EL LUGAR DE LA DIDÁCTICA ESPECÍFICA EN LA FORMACIÓN INICIAL DEL PROFESOR DE MATEMÁTICAS}

\section{RESUMEN}

En este artículo, aportamos cuestiones acerca de la formación inicial de profesores de matemáticas, entresacadas de una investigación cuyo objetivo era conocer, analizar, interpretar y describir el pensamiento, los saberes y las prácticas que los formadores que actúan en la asignatura Didáctica Especial de Matemáticas, en programas de profesorado, vienen movilizando, produciendo y desarrollando. Hemos buscado comprender la naturaleza del conocimiento que ha sido privilegiado en tal asignatura, su importancia y su relación con la práctica de enseñar y aprender matemáticas en las escuelas. Les hemos entrevistado a diez formadores de docentes. El recorte hecho para el artículo ha priorizado el debate acerca de sus prácticas formativas, de su pensamiento respecto a la importancia de la didáctica especial, señalándose, las (in)diferenciaciones entre las disciplinas didáctico-pedagógicas, su lugar curricular en la carrera, las concepciones y prácticas formativas privilegiadas en la asignatura y en el curso de profesorado.

didáctica especial; formación inicial; profesorado de matemáticas. 


\section{INTRODUÇÃO}

Apesar de as reformas curriculares desenvolvidas no início dos anos de 2000 tentarem romper com a lógica do modelo $3+1$ para os cursos de licenciatura, a formação matemática ainda continua distanciada ou desarticulada da formação didático-pedagógica do futuro professor nos cursos de licenciatura em matemática. Esse distanciamento também se evidencia entre as práticas formativas privilegiadas na licenciatura e as práticas de ensinar e aprender matemática na escola básica.

Ainda persiste a concepção de que a formação matemática e a formação para o ensino de matemática são blocos estanques e que pouco dialogam entre si. Ou seja, o trabalho desenvolvido nos cursos de licenciatura em matemática, salvo raras exceções, ainda se centra em dois polos distintos e isolados: um de conhecimentos denominados teóricos e outro de conhecimentos denominados práticos.

O primeiro concentra-se nos conhecimentos academicamente reconhecidos da matemática, negligenciando o papel da prática como geradora de conteúdos de formação. O segundo polo centra-se no fazer pedagógico, por meio de disciplinas como didática especial, prática de ensino, estágio supervisionado, as quais muitas vezes não levam em consideração os conhecimentos que vêm sendo produzidos pela pesquisa acadêmica ou profissional e que poderiam trazer novas significações e compreensões sobre as práticas de ensinar e aprender matemática.

A cisão entre conteúdo e forma, ou entre matemática e didática, entre as disciplinas de conteúdo e as disciplinas de ensino, dentre outras dicotomias que vêm resistindo ao tempo no processo de formação docente, tem sido discutida e problematizada por vários pesquisadores, tais como Fiorentini e Oliveira (2013), Gatti (2000), Moreira (2012), Zeichner (2010).

Gatti (2000) reafirma, com base em suas pesquisas, a presença da dicotomia teoria e prática nesses cursos e o fato de a formação de professores vir constituindo-se, ao longo do tempo, como algo bastante distante da prática escolar da educação básica.

Para Zeichner (2010), a desconexão entre os componentes curriculares acadêmicos e a parcela da formação docente que acontece nas escolas é, ainda, um dos problemas centrais dos cursos de formação de professores.

Nesse contexto, interessamo-nos, de modo particular, pela formação didáticopedagógica do futuro professor de matemática. Trazemos neste texto algumas questões para debate decorrentes de uma pesquisa que teve como foco de estudo a(s) disciplina(s) de didática especial de matemática — ou equivalente(s) — comumente presente(s) na grade curricular dos cursos de licenciatura em matemática. Na pesquisa, buscamos conhecer, analisar, interpretar e descrever os saberes e práticas que vêm sendo produzidos e desenvolvidos por docentes formadores de professores de matemática que atuam na disciplina de didática especial de matemática (ou equivalente) em diferentes cursos de licenciatura em matemática. $\mathrm{O}$ objetivo da pesquisa foi interpretar, analisar e compreender a natureza do conhecimento que tem sido privilegiado nessas disciplinas, bem como sua importância, pertinência e relação com a prática de ensinar e aprender matemática nas escolas. A referida pesquisa integrou um curso de pós-doutorado júnior financiado pelo $\mathrm{CNPq}$, no período 2012-2013, que teve como supervisor o professor doutor Dario Fiorentini, 
da Faculdade de Educação da Universidade Estadual de Campinas (UNICAMP). Os sujeitos da pesquisa foram dez formadores de professores que atuam ou atuaram na disciplina didática especial de matemática, ou equivalente, em universidades públicas do estado do Rio de Janeiro e da cidade de Campinas.

O recorte dessa pesquisa mais ampla, feito para este artigo, priorizou o debate em torno das práticas formativas desenvolvidas do que pensam os formadores acerca da importância da disciplina didática especial de matemática, destacando, sobretudo, as (in)diferenciações entre as disciplinas didático-pedagógicas; seu lugar curricular no curso; as concepções e práticas formativas privilegiadas na disciplina e no curso.

Partimos do pressuposto de que não podemos desconsiderar o peso que a formação de professores pode e deve ter para a transformação da prática escolar. Os futuros professores precisam compreender essas práticas e seus conteúdos específicos de modo que possam organizar com autonomia e responsabilidade política e social experiências de ensino e de aprendizagem matemática que sejam relevantes à formação dos estudantes. Para tanto, e assim como já fora dito por vários outros estudiosos da formação docente (Shulman, 1986, 1987; Tardif, 2002), os saberes dos professores devem ir muito além de meras formulações ou dos procedimentos relacionados aos conceitos e noções das áreas específicas de conhecimento.

Nessa perspectiva, as disciplinas de didática específica podem exercer um papel importante, principalmente se levarmos em conta a complexidade e a amplitude da profissão docente, que envolve desde a gestão da sala de aula até a seleção, retradução, adaptação, produção e utilização de saberes pelos professores, para dar conta de suas tarefas (Tardif, Lessard e Lahaye, 1991; Tardif, 2002).

Nesse sentido, a nosso ver, são de extrema relevância para o debate educacional, no campo da formação de professores de matemática, os estudos e pesquisas que tomam como foco de investigação, na formação inicial, a relação entre os conhecimentos privilegiados pelas disciplinas de didática especial (ou equivalentes) durante o curso de licenciatura e aqueles requeridos e mobilizados na prática de ensinar e aprender matemática. A valorização desse elemento curricular nos impulsionou para essa investigação, com questionamentos postos pela nossa trajetória ao longo de vários anos voltados à formação de professores que ensinam matemática.

A seguir, descrevemos primeiramente os aspectos metodológicos da investigação que gerou este artigo. Depois trazemos os elementos extraídos das análises e dos resultados em seções que abordam: o que os formadores pensam sobre a importância da didática especial de matemática; as (in)diferenciações entre prática de ensino e didática especial da matemática; o lugar curricular da didática especial no curso de licenciatura e as concepções e práticas formativas privilegiadas na disciplina e no curso. À guisa de considerações finais, retomamos questões relevantes discutidas ao longo do texto e, a partir destas, apontamos possíveis caminhos que podem contribuir para repensar a ênfase e o papel das disciplinas didático-pedagógicas em um curso de licenciatura em matemática.

\section{PERCURSO METODOLÓGICO DA INVESTIGAÇÃO}

Os sujeitos da pesquisa foram dez formadores atuantes na disciplina de didática especial de matemática (ou equivalentes) em cursos de licenciatura em 
matemática, sendo oito da cidade do Rio de Janeiro/RJ e dois de Campinas/SP, exercendo suas atividades docentes em universidades públicas.

Em relação à escolha dos sujeitos participantes, foi uma escolha intencional e conveniente aos propósitos do estudo. Tendo em vista o tempo e as condições da pesquisa, delimitamos o campo de investigação aos professores que atuavam em cursos presenciais de licenciatura de universidades públicas na cidade do Rio de Janeiro (cidade onde atua a pesquisadora interessada) e da região de Campinas (região onde atua o supervisor de estágio de pós-doutoramento).

Os contatos iniciais com os formadores foram feitos por intermédio das universidades em que atuam, tendo sido, dessa forma, obtidos o nome e a confirmação de que eram formadores atuantes nas disciplinas de nosso interesse.

No conjunto dos entrevistados, sete eram doutores, dois eram mestres e um, especialista (graduado com especialização). Nove deles eram professores efetivos e um atuava como professor substituto.

As disciplinas em que os entrevistados atuavam apresentam nomes diferenciados, variando de uma instituição para outra, tendo todas, porém, o objetivo de promover a formação didático-pedagógica de futuros professores de matemática. A título de exemplo, encontramos as seguintes denominações para essas disciplinas: didática da matemática, pesquisa e prática de ensino de matemática, prática de matemática, prática em matemática, prática pedagógica em matemática, laboratório de matemática, metodologia do ensino de matemática e educação matemática.

Como pretendíamos conhecer o pensamento e as práticas formativas dos formadores nessas disciplinas, optamos por desenvolver uma pesquisa de natureza qualificativa e interpretativa, tendo como principal instrumento de coleta e produção de informações a entrevista semiestruturada. A observação etnográfica de práticas em sala de aula poderia ter sido uma alternativa para a pesquisa de campo. Entretanto, essa opção seria limitada a uma ou no máximo duas práticas, e isso demandaria muito tempo. Como pretendíamos saber a opinião, o pensamento e as práticas formativas dos professores participantes da pesquisa, as práticas e ideias investigadas foram, portanto, aquelas narradas pelos formadores durante as entrevistas. Assim, esse foi considerado por nós o modo mais viável e apropriado aos propósitos do estudo, pois objetiva responder a questões que dizem respeito ao mundo dos significados e que possui "um lado não perceptível e não captável em equações, médias e estatísticas” (Minayo, 1994, p. 23).

\section{ANÁLISES E RESULTADOS}

A análise feita deu-se com base em um conjunto de questões que consideramos serem significativas das ações estudadas. As categorias com que trabalhamos foram emergentes do material do campo e também inspiradas no confronto entre esse material e a literatura.

Entretanto, em virtude da limitação de espaço para este texto, trazemos aqui algumas análises e resultados decorrentes da pesquisa realizada e que consideramos relevantes para problematizar o papel e o lugar das disciplinas didático-pedagógicas no curso de licenciatura. 
As entrevistas nos colocaram diante de uma infinidade de questões relacionadas ao estudo da formação docente, que podem ser motivadoras de diferentes trabalhos acerca da formação de professores de matemática. Em decorrência da amplitude e da complexidade da tarefa de formar professores de matemática, os formadores, ao narrarem suas práticas e o que pensam acerca da formação didático- pedagógica do professor, trouxeram uma gama significativa de elementos que não dizem respeito, apenas, ao trabalho que realizam na disciplina didática especial de matemática (ou equivalentes), como também à prática de ensino, ao estágio supervisionado e à formação oferecida pelos cursos de licenciatura em matemática, de maneira geral. Somos, entretanto, conscientes de que uma determinada disciplina do curso de licenciatura de matemática é apenas um dos fios que compõem a trama complexa da formação inicial do professor.

Levando em conta as categorias construídas por Fiorentini (2004) para caracterizar os diferentes formadores de professores conforme seu perfil de formação e de prática docente, afirmamos que os formadores entrevistados são formadorespesquisadores. Ou seja, praticamente todos mostraram ter como foco de estudo, pesquisa e prática profissional o campo da formação de professores.

Retomando as categorias de Fiorentini (2004), o pesquisador-formador é aquele formador que prioriza sua prática investigativa em detrimento da docência, considerando esta última como uma atividade secundária ou complementar em sua vida profissional, sendo ela uma das possibilidades de socializar o conhecimento que produz em suas pesquisas. Esse formador geralmente se identifica como matemático ou cientista da educação e raramente procura estabelecer as conexões necessárias entre o que ensina e as necessidades conceituais e didático-pedagógicas dos futuros professores, tendo em vista a prática de ensinar e aprender matemática na escola básica.

Fiorentini (2004) também categoriza o formador-prático, de colaboração esporádica nos cursos de formação, sendo geralmente um formador de campo ou docente escolar, extremamente interessante ao sistema neoliberal por tratar-se de um profissional de baixo custo, de dedicação exclusiva à docência, mas sem a exigência ou estímulo para dedicar-se à pesquisa.

Ser formador-pesquisador é o perfil docente que, de acordo com Fiorentini (2004), coloca (e valoriza) a docência como o seu foco principal de prática e estudo, sendo a pesquisa sobre a própria prática - e também sobre a de outros - o suporte fundamental para a docência como formador de professores de matemática.

\section{O QUE OS FORMADORES PENSAM SOBRE A IMPORTÂNCIA DA DIDÁTICA ESPECIAL DE MATEMÁTICA?}

$\mathrm{Na}$ concepção da maioria dos formadores, a disciplina tem importância fundamental para a formação dos professores de matemática. No entanto, os que atribuem a ela pouca ou nenhuma importância apresentam questões relevantes que nos levam a pensar em outras alternativas de formação que poderiam contemplar aquilo que normalmente se trabalha na disciplina de didática especial de matemática. 
Teria muito mais impacto se, por exemplo, eles vivenciassem isso nas aulas das disciplinas de matemática, utilizando novas metodologias. No curso de licenciatura em matemática, principalmente, o cara, quando tivesse a aula de cálculo, por exemplo, ele teria que ver cálculo com outra metodologia. (Professor 1)

Tanto faz se tem uma disciplina chamada didática especial de matemática ou não. O que importa é saber se existe nessa formação um momento onde nós possamos discutir com os futuros professores essas coisas que estão ligadas à escola. (Professor 9)

Esses questionamentos nos mobilizam a discutir o papel que a disciplina de didática especial de matemática tem nos cursos de licenciatura. Cabe primeiramente observar, como nos alertam Fiorentini (2005) e Lins (2005), que toda disciplina, seja ela específica ou pedagógica, forma didático-pedagogicamente o professor de matemática. O licenciando que estuda cálculo ou análise, por exemplo, não aprende apenas conceitos e procedimentos do cálculo e da análise, aprende também um jeito de estudar, de ser professor e de estabelecer relação com a matemática, podendo ser mais mecânica e procedimental ou mais conceitual e exploratória das ideias matemáticas, dependendo da forma como o professor ensina e faz a gestão da aula. Nesse sentido, formar professores, nos aspectos didático-pedagógicos voltados à docência em matemática, deveria ser objetivo de toda e qualquer disciplina do curso de licenciatura em matemática.

Entretanto, perguntamos: Será que não existem aspectos específicos da atividade docente, relativos ao ensinar e aprender matemática na escola, que precisam ser explorados e problematizados durante a formação e que não poderiam ser contemplados em outras disciplinas da licenciatura? Eis o que dizem alguns formadores entrevistados:

Essa minha disciplina, acho importante, porque ninguém fala de ensino no resto das disciplinas de graduação, pelo que eu percebo. (Professor 3)

É de falar e de formar um indivíduo para lidar com o ensino aí. Aí vai ter que falar sobre coisas que ocorrem no ensino, sobre como a gente planeja o ensino. (Professor 2)

Eu acho essa disciplina fundamental; eu acho, na verdade, que é aquela que caracteriza o curso, sabe? Porque, assim, é... cálculo os engenheiros fazem, matemáticos fazem, físicos fazem. Todo mundo faz. Estatística até médico faz. Mas o que caracteriza a profissão do professor de matemática? (Professor 2)

Os dois últimos depoimentos nos levam a pensar os conhecimentos fundamentais de cada profissão. A matemática que convém à prática do engenheiro ou ao matemático profissional é a mesma que convém à prática de ensiná-la na escola básica? Qual seria o conteúdo fundamental para o profissional do ensino da matemática? 
Conhecer com profundidade a matemática ou os processos de ensinar e aprender, bem como de planejar e avaliar? Entendemos que ambos - esses conhecimentos - deveriam ser apropriados de forma inter-relacionada, porém perguntamos que matemática seria fundamental ao professor? Para nós, a matemática que o professor precisa aprender vai muito além de saber pura e simplesmente a matemática técnica e formal que o habilita a resolver exercícios, problemas e desafios matemáticos do mundo imaginário ou do mundo real.

Para Fiorentini e Oliveira (2013,p. 924), o professor para ensinar matemática enquanto saber de relação - necessita "conhecer, com profundidade e diversidade... não apenas a matemática científica, mas também a matemática escolar e as múltiplas matemáticas presentes e mobilizadas/produzidas nas diferentes práticas cotidianas".

Embora seja possível e desejável organizar a licenciatura de modo que todas as disciplinas possam direcionar suas práticas formativas visando não apenas a uma formação conceitual e procedimental em torno de um conteúdo, mas também à formação de uma cultura matemática ampla e diversificada, explorando aspectos histórico-epistemológicos e didático-pedagógicos, mesmo assim, a nosso ver, isso não seria suficiente para eliminar a disciplina de didática especial de matemática, ou algo equivalente, na grade curricular da licenciatura.

Estudos e discussões sobre planejamento, análise e avaliação da prática pedagógica vigente ou inovadora em matemática nas escolas constituem uma dimensão formativa importante que não pode ser desenvolvida por qualquer disciplina do currículo da licenciatura. Apoiamo-nos em Vieira e Martins (2009) para afirmar que, na didática da matemática, deve ser tratado e problematizado o processo de ensino e aprendizagem de matemática, como ele ocorre na prática cotidiana da escola e em experiências investigativas de mudança dessa prática. Essa didática da prática pode contribuir para uma compreensão mais crítica dos mecanismos de ensinar e aprender na escola básica, abrindo novas possibilidades de organizar e desenvolver o ensino e a aprendizagem, em um processo que envolve desde o planejamento até a análise e avaliação da aprendizagem e do ensino.

A didática tem um papel fundamental, nos cursos de licenciatura. Constitui-se a disciplina que orienta para a prática pedagógica reflexiva atuante no processo de aprendizagem, sistematizando os pontos relevantes que deverão ir ao encontro do que está acontecendo além dos muros das Instituições de Ensino Superior, impactando no sistema educacional brasileiro. (Vieira e Martins, 2009, p. 11.307)

Na perspectiva referenciada por Vieira e Martins (2009), a didática especial de matemática ganha importância como uma disciplina na qual é possível desenvolver um olhar profissional diferenciado para a docência - campo de atuação distinto do bacharel, assim como afirma Moreira (2012, p. 1.144):

A matemática relevante para o matemático não é capaz de fornecer ao professor uma mirada profissional específica para a sala de aula da escola, do mesmo modo que a matemática relevante para a sala de aula da escola é incapaz de fornecer ao futuro matemático uma mirada profissional específica para o traba- 
lho de produção de novos resultados na fronteira do conhecimento acadêmico.

Duas profissões distintas requerem conhecimentos matemáticos distintos.

A mirada profissional à qual Moreira (2012) se refere não implica, a nosso ver, superficializar a matemática a ser aprendida pelo professor. Ao contrário, significa ampliar seus saberes na perspectiva de que ele precisa conhecer a matemática como prática social e saber de relação. Isso implica conhecer matemática para além do campo científico.

\section{(IN)DIFERENCIAÇÕES ENTRE PRÁTICA DE ENSINO E DIDÁTICA ESPECIAL DA MATEMÁTICA}

A pesquisa nos possibilitou constatar que o objeto de estudo dessa disciplina parece ser ainda difuso e pouco compreendido em suas múltiplas dimensões. Apresentando diferentes denominações - como didática da matemática, pesquisa e prática de ensino de matemática, prática de matemática, prática em matemática, prática pedagógica em matemática, laboratório de matemática, metodologia do ensino de matemática, educação matemática - , todas elas parecem tratar de saberes profissionais, metodologias de ensino e dos processos de planejamento e avaliação do ensino e da aprendizagem. No entanto, ao perguntar aos formadores sobre o que diferencia uma denominação de outra, os depoimentos evidenciam certa indiferenciação entre elas:

Eu acho que não está muito bem definido no próprio campo o que é uma coisa e o que é outra. Acho que, pelo próprio conjunto, pela estrutura curricular da licenciatura. (Professor 4)

Não sei se eu saberia dizer o que é uma coisa e o que é outra, e nem se o modelo ideal seria com essas coisas realmente dissociadas. (Professor 3)

Não existe mais nada na [universidade F], na licenciatura em matemática, que se chame didática especial da matemática. Está tudo dentro da prática de ensino. (Professor 4)

Essa indiferenciação também foi evidenciada pelo estudo de Ferreira (2011), ao tentar conhecer o processo de disciplinarização da metodologia do ensino de matemática nos cursos de licenciatura em matemática públicos de São Paulo. A pesquisadora verificou que essas disciplinas de formação didático-pedagógica presentes na grade curricular dos cursos apresentam abordagens e objetivos semelhantes e todas elas têm como foco formar o professor em uma perspectiva didático-pedagógica, tendo como referência a escola básica. A autora percebeu também que a disciplina vem mudando de nome ao longo do tempo, tendo passado de didática de matemática para prática de ensino de matemática, e destas para metodologia do ensino de matemática ou prática pedagógica em matemática. Além disso, ainda 
segundo Ferreira (2011), a disciplina teria passado de uma visão inicial de que para ser professor seria suficiente o conhecimento dos conteúdos e de alguma didática para uma outra visão que denota maior valorização da prática como componente fundamental à formação docente.

Foi nesse contexto que a "prática de ensino de matemática" institucionalizouse como uma disciplina pedagógica do curso de formação de professores. Segundo a pesquisadora, houve de fato uma mudança nos currículos nos anos de 1960 da didática especial para a prática de ensino, mas acompanhada também de uma mudança de concepção, que era a de incorporar nos cursos de formação de professores um trabalho vinculado aos colégios de aplicação. Ainda entendidos como insuficientes o conteúdo, a didática e a prática para a formação do professor, a adoção do termo metodologia do ensino de matemática busca acrescentar formas de pensar o ensino de matemática como campo específico de conhecimentos práticos e teóricos, trazendo um olhar mais próprio da identidade do professor de matemática (Ferreira, 2011).

\section{O LUGAR CURRICULAR DA DIDÁTICA ESPECIAL NO CURSO DE LICENCIATURA}

Não raro, o trabalho na didática especial de matemática, em suas diferentes denominações, encontra-se desarticulado do estágio supervisionado, tendo em vista que, geralmente, formadores diferentes são responsáveis por cada um desses trabalhos na licenciatura.

Não sei do que acontece na prática de ensino. Não tenho a menor ideia de como é que é. Não está no meu departamento, está no departamento de matemática. (Professor 1)

A minha disciplina se chama metodologia do ensino da matemática, com quatro horas por semana. E o estágio não está no mesmo período. E isso dificulta. Mas isso foi um preço que a gente pagou ao antecipar. (Professor 5)

Os depoimentos desses professores colocam em evidência o distanciamento temporal e físico entre o estágio e a disciplina de metodologia ou didática especial da matemática. Isso impede que as vivências de estágio dos licenciandos nas escolas sejam objeto ou foco de reflexão e investigação no curso, de modo particular nas disciplinas de formação didático-pedagógicas para o ensino de matemática. Ou seja, fica praticamente inviabilizada uma prática de análise, investigação e problematização sobre a atividade matemática na escola, ou sobre a própria prática do licenciando (Oliveira, 2011).

$\mathrm{Na}$ verdade, a separação temporal e curricular do estágio das outras disciplinas de formação didático-pedagógica da licenciatura está atrelada a uma questão mais ampla, que é o distanciamento entre o trabalho realizado na universidade e o realizado na escola. 
A grande lacuna da licenciatura em si, pra mim, você sabe que eu acho que continua sendo a relação com a escola básica. (Professor 8 )

$\mathrm{Na}$ estrutura do curso é onde eu sinto falta disso. Às vezes um professor ou outro faz uma relação ou outra, ficando quase uma colcha de retalhos. Retalhos a serem alinhavados... Alguns alunos alinhavam, outros não. (Professor 8)

Esse distanciamento parece ser ainda mais problemático se considerarmos o trabalho nas disciplinas "duras", as quais tendem a reforçar ainda mais esse distanciamento entre universidade e escola ou entre os conteúdos da formação matemática e os conteúdos da atividade profissional. Não parece ser feita, nas aulas dessas disciplinas, qualquer relação entre o que nelas se desenvolve com a futura atuação dos professores na escola básica, segundo os formadores entrevistados.

Para Zeichner (2010), reconhecido estudioso da formação docente, a desconexão entre os componentes curriculares acadêmicos e a parcela da formação docente que acontece nas escolas é um dos problemas centrais dos cursos de formação de professores e reforça a dicotomia entre teoria e prática. Para Pimenta e Gonçalves (1990, p. 129), "um curso não é a prática docente, mas é a teoria sobre a prática docente e será tão mais formador à medida que as disciplinas todas tiverem como ponto de partida a realidade escolar brasileira".

Nossa pesquisa mostra o que, a princípio, parece representar um avanço curricular. Há, em algumas instituições, a presença da prática de ensino desde o início do curso de formação, garantindo que os licenciandos tenham contato com a prática de ensinar e aprender matemática ao longo de todo o curso de licenciatura.

O nome da disciplina é prática de ensino. São oito práticas, desde que o indivíduo entra. Efetivamente entra desde o primeiro período. (Professor 2)

No entanto, a avaliação do sucesso dessa iniciativa nem sempre é avaliada, e se for avaliada não pode deixar de levar em conta o que se faz, efetivamente, nessa disciplina e, sobretudo, como ela dialoga ou se relaciona com as demais disciplinas do curso.

\section{CONCEPÇÕES E PRÁTICAS FORMATIVAS PRIVILEGIADAS NA DISCIPLINA E NO CURSO}

$\mathrm{Na}$ maioria das práticas e ideias narradas pelos formadores, insinua-se uma mistura de perspectivas de entendimento de qual é o conhecimento necessário ao professor, levando-se em conta as categorias de Cochran-Smith e Lytle (1999, 2009). Entendemos que as práticas formadoras nas disciplinas de didática especial de matemática (ou equivalentes) apresentam nuances de uma concepção de que os professores devem desenvolver um conhecimento para a prática e também um conhecimento da prática. Apesar de as pesquisadoras referirem-se às comunidades investigativas, o que não é propriamente o espaço de sala de aula dos cursos de licenciatura em matemática — salvo algumas exceções sobretudo ligadas ao Programa 
Institucional de Bolsas de Iniciação à Docência $(\mathrm{PIBID})^{1}$ e Programa Observatório da Educação (OBEDUC) —, ${ }^{2}$ apoiamo-nos no entendimento que estas têm acerca do conhecimento do professor em sua relação com a prática pedagógica escolar.

A maioria das práticas formativas privilegiadas na licenciatura em matemática assume a perspectiva de que o professor necessita desenvolver um conhecimento para a prática e adota uma visão instrumental na relação entre teoria/pesquisa/conhecimento e prática. Nessa perspectiva, ensinar é um processo de aplicação, em uma situação prática, de um conhecimento recebido: os professores traduzem, implementam, usam, adaptam e colocam em prática o que aprenderam da base de conhecimento.

Nessa concepção, segundo Cochran-Smith e Lytle (1999, 2009), os pesquisadores universitários, em diferentes disciplinas, são vistos como especialistas que produzem o conhecimento formal e as teorias para serem aprendidas e aplicadas pelos professores na prática profissional. Essa ideia tem como pressuposto que saber mais leva diretamente a uma melhor prática. A maioria das práticas formativas investigadas apoia-se na ideia de que, na formação, ensina-se a ensinar.

Eu selecionei os números inteiros, e aí discuti quais são as principais questões e dificuldades que há na aprendizagem nos inteiros. O que significa para o aluno tirar mais do que ele tem, o que significa para o aluno tirar de um negativo, coisas desse tipo. (Professor 1)

Supõe-se que os professores em formação devam aprender as teorias na universidade para depois ir às escolas e praticar ou aplicar o que foi aprendido no espaço acadêmico (Korthagen e Kessels, 1999; Tom, 1997 apud Zeichner, 2010).

Uma segunda concepção de conhecimento do professor que encontramos presente, embora com menor frequência, nas práticas formadoras da graduação é o conhecimento da prática, o qual não pode ser dividido em formal e prático. $\mathrm{O}$ conhecimento que os professores precisam para ensinar é gerado quando eles consideram suas próprias salas de aula como locus de investigação intencional, ao mesmo tempo em que levam em conta a teoria e o conhecimento produzidos por outros, pois estes ajudam a provocar questionamentos e interpretações da prática (Cochran-Smith e Lytle, 1999).

Embora todos os professores aprendam conhecimentos na prática, esses conhecimentos podem tornar-se da prática (no sentido de Cochran-Smith e Lytle), se os professores ou futuros professores fizerem parte de comunidades de investigação, teorizando e construindo seu trabalho de forma que possa conectá-lo a questões sociais, culturais e políticas, gerando um conhecimento local da prática.

1 Programa que objetiva o aperfeiçoamento da formação de professores para a educação básica promovendo a inserção, desde o início da formação, dos estudantes de licenciaturas nas escolas públicas.

2 Programa que visa ao incentivo a pesquisas em educação, envolvendo instituições de educação superior e as bases de dados existentes no Instituto Nacional de Estudos e Pesquisas Educacionais "Anísio Teixeira” (INEP). 
Ou seja, a pesquisa do professor é uma maneira de ele conhecer o ensino localmente, estabelecendo interlocução com conhecimentos universais.

Nessa perspectiva, o conhecimento é inseparável do sujeito que conhece. As salas são entendidas como local de investigação, bem como os coletivos escolares e as comunidades de investigação. Nesses espaços, os professores problematizam seu próprio conhecimento, bem como o conhecimento e a prática dos outros. Ou seja, o conhecimento é construído coletivamente, em comunidades locais ou amplas. Todos aprendem com todos, não preponderando a ideia de "perito"(Cochran-Smith e Lytle, 1999).

Para essas autoras, a prática é mais que prática, pois pode ser crítica, política e intelectual. Além disso, engloba o trabalho do professor dentro e além da ação imediata da sala de aula. A investigação é mais que a concretização do conhecimento prático do professor. O conhecimento emana da investigação sistemática do ensino, dos estudantes e do aprendizado, da matéria, do currículo e da escola. Temos que ter professores assumindo papéis de liderança e protagonismo na busca da transformação das salas de aula, das escolas e da sociedade.

Tomando como referência as concepções de Cochran-Smith e Lytle (1999), identificamos que alguns formadores norteiam-se pela ideia de que o conhecimento necessário ao professor é um conhecimento para a prática, sobretudo quando dizem instrumentalizar os futuros professores para a sua futura prática e priorizam a formação didático-pedagógica em matemática voltada ao como devem planejar, ensinar e avaliar.

De outra parte, observamos indícios de uma perspectiva de entender o conhecimento do professor como um conhecimento da prática, quando mostram acreditar que os professores aprendem ao problematizarem suas próprias suposições, analisando e investigando aspectos subjacentes e importantes da prática vigente ou alternativa (Cochran-Smith e Lytle, 1999), como evidencia o Professor 9:

Os conteúdos matemáticos escolares entram na educação matemática I e II em algum momento, mas nunca com o propósito de como ensiná-los, é com o propósito de problematizar sempre a escola que existe atualmente, o modo como eles estão na escola atualmente. (Professor 9).

Quando perguntados sobre os conteúdos e metodologias de suas aulas, os formadores, em sua maioria, indicaram parecer orientar suas práticas formadoras selecionando os conteúdos em relação direta com a escola básica, sejam os conteúdos do $6^{\circ}$ ao $9^{\circ}$ ano, bem como os do ensino médio.

$\mathrm{Na}$ verdade, a gente fez assim... Tem esse nome prática, mas é como se fosse a prática teórica. É onde a gente, de alguma maneira, revisita assuntos do ensino básico, são questões assim... trabalhar com frações... (Professor 6)

Nesse sentido, destacamos esse como um aspecto positivo do trabalho de formação realizado por alguns formadores, apesar da diversidade de prioridades e ênfases que encontramos nas diferentes práticas.

Essa diversidade talvez possa ser o reflexo do que Ball (2000) apresenta como os três grandes problemas a serem enfrentados na formação docente. $\mathrm{O}$ primeiro 
consiste em identificar o conhecimento de conteúdo que importa para o ensino; o segundo resume-se em considerar como tal conhecimento tem que ser estudado e compreendido para ser ensinado; e o terceiro consiste em criar oportunidades de aprendizagem do conteúdo de modo que possa capacitar os futuros professores não somente a ter domínio do conhecimento desses conteúdos, mas também saber utilizá-los ou explorá-los em contextos variados de prática.

Em meio à diversidade de escolhas e abordagens, não observamos uma perspectiva conteudista de formação docente na disciplina didática especial de matemática (ou equivalente), mas, sim, um trabalho no âmbito da abordagem de recursos para o ensino dos conteúdos, na perspectiva de desenvolver um conhecimento para a prática (Cochran-Smith e Lytle, 1999). Esta parece ser uma tendência predominante na disciplina de didática especial e que envolve um conhecimento acerca do como fazer, mas que interliga aspectos conceituais da matemática com os aspectos didático-pedagógicos e curriculares do ensino da matemática. Essa perspectiva ajuda a romper com a tradicional dicotomia entre formação matemática e formação didático-pedagógica.

Leituras e discussão de textos, atividades com materiais, elaboração de atividades, que conteúdos do ensino básico podem ser explorados com esse recurso... (Professor 7)

Trago para sala de aula o Tangram... a gente tem oficinas... então, por exemplo, tem uns jogos que são direcionados para a pessoa no final concluir a fundamentação da fórmula de Bhaskara... (Professor 5)

\section{DISCUSSÃO FINAL}

Os formadores entrevistados, ao problematizarem suas práticas, fizeram emergir diversos aspectos de seu trabalho. Referimo-nos a uma amplitude de questões, afins e interrelacionadas, que nos trouxeram dificuldades para diferenciá-las e categorizá-las.

A disciplina que trata da formação didático-pedagógica do futuro professor de matemática está presente na grade curricular dos cursos de licenciatura com diferentes denominações, daí o fato de nos referirmos, neste texto, à didática especial de matemática ou equivalentes.

Com base nos depoimentos dos formadores entrevistados, surgiram não só questões específicas da didática de matemática, como também questões que dizem respeito aos cursos de licenciatura. Em suas falas observam-se críticas ao modelo 3+1, que, apesar de disfarçado, encontra-se vigente; ao estágio ainda isolado das demais atividades e disciplinas da licenciatura, salvo algumas exceções; ao distanciamento do trabalho do formador em relação à complexidade das práticas escolares; ao trabalho das disciplinas ditas "duras", com as quais o futuro professor de matemática da escola básica não se identifica; ao descrédito atribuído às disciplinas do eixo profissional.

O trabalho realizado na disciplina de didática especial de matemática, em grande maioria das práticas estudadas, parece colocar em seu foco a matemática do $6^{\circ}$ ao $9^{\circ}$ ano, mesclando aspectos conceituais e didático-pedagógicos, visando ao trabalho escolar, priorizando a perspectiva do como fazer. 
O distanciamento entre o trabalho feito na disciplina (na universidade) e as atividades de estágio, decorrentes de questões curriculares que dificultam um trabalho articulado, compromete ou até inviabiliza a análise das práticas, o que deveria ser uma estratégia predominante, na perspectiva de entender e valorizar a disciplina de didática especial de matemática como um espaço de análise e problematização das práticas escolares reais e complexas.

Nesse sentido, a pouca importância atribuída à disciplina por parte de alguns formadores entrevistados, que questionam a forma como ela opera e explora os saberes e práticas profissionais, muito contribuiu para reafirmarmos a importância que consideramos que essa disciplina pode e deve ter no processo de formação inicial do professor. Entendemos que suas críticas apontam caminhos que podem contribuir para repensar a ênfase e o papel das disciplinas didático-pedagógicas em um curso de licenciatura em matemática.

Um desses papéis seria o de problematizar o lugar e a importância da matemática na prática escolar, questionando que matemática seria essa e relacionando-a com as múltiplas práticas sociais que mobilizam saberes matemáticos, sendo a prática social do matemático apenas uma dessas práticas sociais, conforme Fiorentini e Oliveira (2013).

Além disso, outro papel seria o de analisar e problematizar, conforme Martins (2008), o processo real de ensino e aprendizagem da matemática escolar, questão central na atividade docente, de modo que o professor possa adquirir autonomia e condições críticas para promover a transformação da prática pedagógica. Em síntese, entendemos que a disciplina didática especial de matemática ainda possui um papel formativo relevante e fundamental para o desenvolvimento dos saberes e práticas profissionais dos futuros professores de matemática, devendo, entretanto, ser ressignificada e articulada à possibilidade de transformação e melhoria das práticas escolares.

Nesse sentido, é urgente que tanto a formação conceitual quanto a formação didático-pedagógica da matemática estejam articuladas e contextualizadas no cotidiano escolar do ensino e aprendizagem de matemática. A análise e problematização das práticas de ensinar e aprender matemática na escola é um dos caminhos. A disciplina de didática especial de matemática ou equivalente poderia assumir esse papel.

Uma coisa, no entanto, é certa: precisamos aprofundar a discussão acerca do que deve ser tratado nas licenciaturas sobre matemática e seu ensino, considerando-se a realidade de tempo que se tem e as questões nodais do ensino e aprendizagem de matemática, estabelecendo efetivas relações entre a formação dos professores e sua futura prática em matemática, tentando romper com a tricotomia apontada por Fiorentini e Oliveira (2013, p. 933), a qual se revela presente nesses cursos, de acordo com os entrevistados:

(1) a formação matemática voltada quase exclusivamente à matemática acadêmica, sem estabelecer relações e problematizações com a matemática escolar e com a perspectiva didático-pedagógica; (2) a formação didático-pedagógica, geralmente dissociada da matemática acadêmica e das práticas reais (vigentes ou inovadoras) de sala de aula nas escolas atuais; e (3) a prática profissional, que trabalha uma matemática mais alinhada a uma tradição escolar e distante da matemática que a licenciatura privilegia e, de outro lado, que possui/desenvolve uma prática didático-pedagógica construída, tendo por base uma tradição pedagógica e/ou o enfrentamento consciente dos problemas e desafios das diferentes realidades complexas da escola brasileira. 
As questões que a pesquisa nos apresenta merecem discussão e reflexão internas, nas instituições formadoras, em fóruns de formação de professores e de discussão das licenciaturas. De modo particular, os fóruns promovidos pela Sociedade Brasileira de Educação Matemática, principalmente por seu Grupo de Trabalho de Formação de professores, os Fóruns de Licenciaturas em Matemática, bem como o Grupo de Trabalho de Educação Matemática da Associação Nacional de Pós-Graduação e Pesquisa em Educação (ANPEd) (GT19), constituem-se em espaços privilegiados para essa problematização.

\section{REFERÊNCIAS}

BALL,D. L. Bridging practices: intertwining content and pedagogy in teaching and learning to teach.Journal of Teacher Education, Washington: AACTE,v.51,n.3,p.241-247,May/June 2000. Cochran-Smith, M.; Lytle, S. L. Relationships of knowledge and practice: teacher learning in communities. Review of Research in Education, Washington: AERA, n. 24, p. 249-305, 1999. (Tradução livre do Grupo de Estudo e Pesquisa em Formação de Professores de Matemática - GEPFPM, FE/UNICAMP). .; . Inquiry as stance: practitioner research for the next generation. New York: Teachers College Press, 2009.

Ferreira, V. L. Metodologia do ensino de matemática: história, currículo e formação de professores. São Paulo: Cortez, 2011.

Fiorentini, D. A investigação em educação matemática sob a perspectiva dos formadores de professores. In: Seminário de Investigação em Educação Matemática, 15., 2004, Covilhã, Portugal. Anais... Lisboa: APM, 2004, p. 13-35.

. A formação matemática e didático-pedagógica nas disciplinas da licenciatura em matemática. Revista de Educação PUC-Campinas, Campinas: PUC, n. 18, p. 107-115, jun. 2005. Fiorentini, D.; Oliveira, A. T. C. C. O lugar das matemáticas na licenciatura em matemática: que matemáticas e que práticas formativas? Bolema, Rio Claro: UNESP, v. 27, n. 47, p. 917-938, dez. 2013.

Gatti, B. A. Formação de professores e carreira: problemas e movimentos de renovação. 2. ed. Campinas: Autores Associados, 2000.

Korthagen, F.; Kessels, J. Linking theory and practice: changing the pedagogy of teacher education. Educational Researcher, Washington: AERA, v. 28, n. 3, p. 4-17, 1999. Lins, R. C. Formação pedagógica em disciplinas de conteúdo matemático nas licenciaturas em matemática. Revista de Educação PUC-Campinas, Campinas: PUC, n. 18, p. 117-123, jun. 2005.

Minayo, M. C. S. (Org.). Pesquisa social. Teoria, método e criatividade. Petrópolis: Editora Vozes, 1994.

Martins, P. L. O. Didática. Curitiba: IBPEX, 2008.

Moreira, P. C. $3+1$ e suas (in)variantes (Reflexões sobre as possibilidades de uma nova estrutura curricular na licenciatura em matemática). Bolema, Rio Claro: UNESP, v. 26, n. 44, p. 1.137-1.150, dez. 2012. 
Oliveira, A. T. C. C. O estágio supervisionado de matemática como processo de investigação e de aprendizagem da docência: o Caso de Cristina. Perspectivas da Educação Matemática, Campo Grande: UFMS, v. 4, p. 97-110, 2011.

Pimenta, S. G.; Gonçalves, C. L. Revendo o ensino de $2^{\circ}$ grau - propondo a formação de professores. São Paulo: Cortez, 1990.

Shulman, L. S. Those who understand: knowledge growth in teaching. Educational Researcher, Washington: AERA, v. 15, n. 2, p. 4-14, 1986.

. Knowledge and teaching: foundations of the new reform. Harvard Educational Review, Cambridge, MA: Harvard Education Publishing Group, v. 57, n. 1, p. 1-22, 1987.

Tardif, M.; Lessard, C.; Lahaye, L. Os professores face ao saber: esboço de uma problemática do saber docente. Teoria e Educação, Porto Alegre: Pannônica, n. 4, p. 215-233, 1991.

TARdif, M. Saberes docentes e formação profissional. Petrópolis: Vozes, 2002.

Tom, A. Redesigning teacher education. Albany: SUNY Press, 1997.

Vieira, D. C. O.; Martins, P. L. O. As disciplinas de didática nos cursos de licenciatura. Congresso Nacional de Educação, 9., 2009; Encontro Sul Brasileiro de Psicopedagogia, 3. 2009, Curitiba. Anais... Curitiba: PUC-PR, 26 a 29 out. 2009, p. 11.303-11.311.

Zeichner, K. M. Repensando as conexões entre a formação na universidade e as experiências de campo na formação de professores em faculdades e universidades. Tradução de Marcelo de Andrade Pereira. Educação, Santa Maria: UFSM, v. 35, n. 3, p. 479-504, set./dez. 2010.

\section{SOBRE OS AUTORES}

Ana Teresa de Carvalho Correa de Oliveira é doutora em educação pela Pontifícia Universidade Católica do Rio de Janeiro (PUC-Rio). Professora da Universidade Federal do Rio de Janeiro (UFRJ).

E-mail: anateresa@fe.ufrj.br

Dario Fiorentini é doutor em educação pela Universidade Estadual de Campinas (UNICAMP). Professor da mesma instituição.

E-mail:dariof@unicamp.br

Recebido em 16 de fevereiro de 2016

Aprovado em 19 de dezembro de 2016 